\title{
Joint efforts needed to prevent traffic accidents, injuries and fatalities
}

\author{
M. Mikusova \\ Faculty of Operation and Economics of Transport and Communications, \\ University of Zilina, Slovakia
}

\begin{abstract}
The paper presents the global situation in road safety and describes the current situation in several European counties, drawing attention to the adverse developments in some of them. It presents the approach of the international project SOL in relation to strengthen road safety management capacity in the region of Central Europe. It underlines the added value of networking and contains recommendations for building multi-stakeholder partnerships for road safety at a national, regional and community level. It also provides a resume of stakeholder assessment undertaken in Zilina region.
\end{abstract}

Keywords: traffic accidents, networking, road safety, partnerships, strategy.

\section{Introduction}

The degree of road transportation and motorization is constantly increasing. Apart from the undoubted advantages, it causes a heavy loading of the road network and constantly increasing demands on traffic and its safety. Road safety actually is not only an important traffic and social issue but also an economic one.

There is universal recognition of the tremendous global burden resulting from road traffic crashes, and that road traffic injuries constitute a major but neglected public health problem that has significant consequences in terms of mortality and morbidity and considerable social and economic costs. According to the WHO and the World Bank, a multi-sectorial approach is required to successfully address this problem [4]. While the number of deaths and seriously injured people is falling, studies have shown that faster progress is possible if all effective means are applied [3]. 
Road crashes and road crash injuries are no longer seen as "an inevitable outcome of road transport" but rather as "largely preventable and predictable". A core component of this "new paradigm" is the recognition that road safety is a multi-sectorial issue and a public health issue - all sectors need to be fully engaged in responsibility, activity and advocacy for road crash injury prevention. Good infrastructure and vehicles must be complemented with common sense everyday human behaviours and effective trauma care services [1].

\section{Global road safety situation}

Nearly 1.3 million people die each year on the world's roads and between 20 and 50 million suffer non-fatal injuries. Over $90 \%$ of these fatalities occur in lowincome and middle-income countries. In 2004, road traffic injury was ninth in the leading causes of death, but it is estimated by WHO that by 2030 , without concerted action, road traffic will be at fifth place ahead of such diseases as tuberculosis and HIV/AIDS resulting in an estimated 2.4 million deaths each year. Road traffic injuries are already among the three leading causes of death for people between 5 and 44 years of age. The economic consequences of motor vehicle crashes have been estimated between $1 \%$ and $3 \%$ of the respective GNP of the world countries, reaching a total over $\$ 500$ billion [11].

Growing concern about the growing loss of life on the world's roads was highlighted by the publication of the World report on road traffic injury prevention [4] in 2004 and the call for action from the Commission for Global Road Safety in 2006. The second Make Roads Safe report [8] in 2009 proposed a "Decade of Action" and in November 2009 the First Ministerial Conference on Road Safety was held in Moscow and endorsed the call for the Decade. The conference brought together transport and health ministers from 80 countries and officials and delegates from more than 130 countries.

In March 2010, the United Nations proclaimed the Decade of Action for Road Safety 2011-2020. The overall Goal of the Decade is to stabilize and then reduce the forecast level of road traffic fatalities around the world by 2020 . It is estimated by the Commission for Global Road Safety that if this ambitious goal can be achieved up to 5 million lives could be saved and 50 million serious injuries could be prevented over the course of the Decade.

In support of the Decade's aims a Global Plan of action sets out specific objectives for the achievement of the Goal that include developing and implementing road safety strategies and targets; strengthening road safety management structures; improving the quality of data collection and monitoring progress; encouraging increased funding to road safety; and building capacity at regional, national and global level to improve road safety.

The Global Plan is based on the "safe system" approach and encourages countries to implement activities, within the legal constructs of national and local governments, according to five pillars. The five pillars for national activities are: Road safety management, Safer roads and mobility, Safer vehicles, Safer road users, and Post-crash response. Countries should consider these five areas within 
the framework of their own national road safety strategy, capacity and data collection systems.

Activities in each of the five areas should be based on the recommendations of the World report on road traffic injury prevention [4] and should address the key road crash risks: speeding, drink driving, and lack of use of helmets, seat belts, and child restraints. The WHO has produced a series of manuals for decision makers and practitioners to address these key risks, as well as a manual giving guidance on data systems. Within the framework of the five pillars each country's priorities for action will depend on local conditions, and road safety measures should be adapted accordingly.

In 2009, the WHO published the first Global Status Report on Road Safety that assessed the road safety situation in 178 countries, using data drawn from a standardized survey. The results show that road traffic injuries remain an important public health problem, particularly for low-income and middle-income countries. Pedestrians, cyclists and motorcyclists make up almost half of those killed on the roads, highlighting the need for these road users to be given more attention in road safety programmes. The results suggest that in many countries road safety laws need to be made more comprehensive while enforcement should be strengthened. The report results clearly show that significantly more action is needed to make the world's roads safer. An updated report that is serving as a baseline for monitoring national and international progress towards the achievement of the objectives - Global Status Report on Road Safety 2013 [11] has been published recently.

\subsection{The actual road traffic safety situation in Europe}

Road safety is a major societal issue in Europe because about $80 \%$ of Europeans live in cities. European cities are suffering heavily from congestion high levels of pollution, noise, and road crashes, largely caused by excessive use of the private car. Road strategy depends greatly on how communities choose to manage their transport systems in relation to their overall health and safety objectives and how they are balanced with economic, social and environmental considerations [1]. The growing trend away from public transport, walking and cycling towards motorized transport has marked a move towards modes and means of transport that pose comparatively higher costs to society economically, environmentally, and in health terms.

Figure 1 shows road traffic fatalities per million inhabitants in 2001 and 2011. The average for the EU was 60 in 2011. Fatality rates fell over the period in all EU countries. As usually the lowest rates were reached by western European countries: Sweden, the UK, Denmark and the Netherlands, where fatality rates ranged from 31 to 40 . 


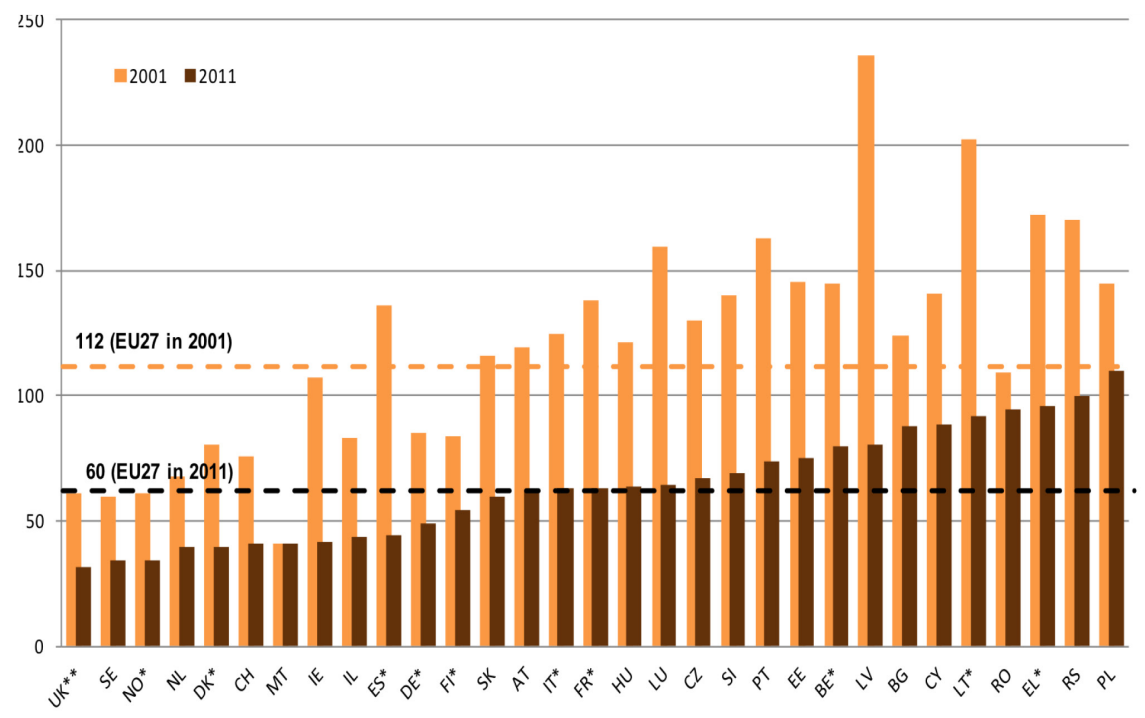

Figure 1: Road traffic fatality rates in EU countries 2001 and 2011 [10]. (*Provisional estimates were used for 2011 as the final figures for 2011 were not available at the time of going to print. **UK estimate based on 3\% increase in killed in 2011 Q1-3 compared with 2010 Q1-3.)

Acording to statistics published by The European Commission in the summer 2011, EU road fatalities decreased by $11 \%$ in 2010. In 2011 - the first year of the 2020 Road Safety Target - the overall number of road deaths decreases compared with precious year but reduction slows down (to $-2 \%$ ). This was the slowest decrease in road deaths in a decade (wide reduction throughout the last decade was on average $-6 \%$ ). However country by country statistics show that the number of deaths still varies greatly across the EU. Whereas in some European countries the road safety situation has improved constantly over the past decades, in many others the road safety challenge has not been addressed so successfully and number of road fatalities is still very high.

In 2011 performance was variable with 12 of the 27 countries experiencing an increase in deaths, including three of the SOL countries, Poland, Slovenia and Germany. Hungary and the Czech Republic on the other hand had falls in deaths of $14 \%$ and $12 \%$ respectively, significantly above the EU average. The EU average reduction in road deaths over the period $2001-2011$ was $45 \%$, and seven SOL countries had reductions within about $+/-10 \%$ of the EU average, with the largest falls in Hungary and Slovenia. Only Poland had a significantly worse than average performance with deaths falling by only 24\%. On 20th June 2012 the Road Safety PIN Award for Outstanding Progress in Road Safety 2012 was 
awarded to Hungary in recognition of the reduction of $49 \%$ in road traffic deaths since 2001.

In 2011 rates were up to $10 \%$ above the EU average in majority of SOL project countries. Road fatality numbers in Italy (63), Austria (62), Hungary (64) were upon average, in Slovakia at average (60) and higher than average were in Slovenia (69), the Czech Republic (67) and Poland (110) with the highest rate (in which is this country now the worst performing country in the EU, and the only one with a fatality rate over 100 per million). Conversely, in Germany the rate of 49 was significantly below the EU average.

Table 1: $\quad$ Number of road fatalities in SOL project countries. $[6,7,9]$.

\begin{tabular}{|c|c|c|c|c|c|}
\hline & 2001 & 2010 & 2011 & $2001-2011(\%)$ & $2010-2011(\%)$ \\
\hline Austria & 958 & 552 & 523 & -5.2 & -45.4 \\
\hline Czech Republic & 1,334 & 802 & 707 & -11.8 & -47.0 \\
\hline Germany & 6,977 & 3,648 & 4,002 & +9.7 & -42.6 \\
\hline Hungary & 1,239 & 740 & 638 & -13.8 & -48.5 \\
\hline Italy & 6,691 & 4,090 & 3,800 & -7.1 & -43.2 \\
\hline Poland & 5,534 & 3,907 & 4,189 & +7.2 & -24.3 \\
\hline Slovakia & 614 & 353 & 324 & -8.2 & -47.2 \\
\hline Slovenia & 278 & 138 & 141 & +2.1 & -49.2 \\
\hline
\end{tabular}

Table 1 shows that performance in the SOL countries in 2011 compared with 2010 was mixed. Fatality rates fell most in Hungary and the Czech Republic, and also fell in Austria, Italy, and Slovakia, but increased in Germany, Poland, and Slovenia. However, over the decade 2001-2011 performance in the SOL countries, except Poland, compares favorably with countries such as Belgium, Bulgaria, Estonia, and Romania that were at similar levels in 2001, or in the case of Romania lower, but in 2011 all had fatality rates well above the SOL countries, except Poland.

Although, with the exception of Poland, the seven countries with pilot activities in the SOL project (Germany is also a partner country but there is no pilot in Germany) have made significant progress and are now broadly average performers in terms of reductions in deaths and in fatality rates, there is a considerable gap between them and the best performing countries, Sweden, the UK, and the Netherlands. There is therefore great potential for road safety improvement in this group of Central European countries.

This road safety challenge has reached a magnitude that even puts the overall competitiveness, the attractiveness as location for working and investments as well as the quality of life in the most seriously affected parts of the cooperation area at considerable risk. Road crashes have a severe negative impact on the social and economic situation in respective countries, costing up to $2 \%$ or more of the GDP [8].

Even though there are several good practice examples of road safety management, severe joint efforts are required by all relevant stakeholders on all levels to make a contribution to reach the overall policy goal set by the European Commission - decrease the number of road crashes by $50 \%$ in the midterm. 
There is a lack of national and local government commitment to road crash/trauma prevention and sustainable transport in many countries. Even where national strategies exist the political commitment is often lacking to ensure these policies are properly implemented at all levels of government. Progress in reducing road crashes/trauma and promoting sustainable transport is hampered by the fact that management, implementation and resources are largely concentrated at the national level. In addition, the responsible national departments are thinly staffed and there are generally weak links to community level government to facilitate local level action and enable the implementation of national policies at the community level even though legal frameworks allow for local government action in road safety and transport planning.

At the community level, dedicated multidisciplinary institutional structures to manage effective road safety and sustainable transport programs are generally very weak or lacking entirely. This weakness is compounded by a lack of well trained professionals with the knowledge and skills to develop, implement, monitor and evaluate effective long-term road safety and sustainable transport programs, grounded in a multidisciplinary systems approach.

Experience from countries with the best road safety records showed that the delivery of effective road safety and sustainable transport interventions is most successful when action is coordinated among different levels of government, from national to the community level and different sectors and disciplines. It is important that local government and local professionals are actively involved and supported in the delivery of national policies because they are in the best position to turn national objectives into local solutions [2].

\section{Approach of the SOL project}

"Save our Lives - A comprehensive road safety strategy for Central Europe," (SOL) is a project cofinanced by the European Programme of Territorial Cooperation "Central Europe". It represents a significant regional road safety programme and it is contributing to global road safety with critical knowledge, experience and road safety tools. SOL involves the eight EU countries covered by the Central Europe programme: Germany, Italy, Austria, Slovenia, Slovakia, Poland, the Czech Republic and Hungary.

It is supporting twelve pilot communities in seven countries in the region to strengthen their approaches to road safety and sustainable mobility in order to prevent death and injury caused by road crashes. The project vision is " $A$ region free of road-crash death and injury, safe for all road users in every community”. The supporting principles of this vision are interdisciplinary and self-completing: multi-stakeholders partnership, road safety management, good practice analysis, transnational learning and networking, active involvement of SOL communities, evidence based, data driven and results focused activities, development of innovative projects and programmes. The project aims at giving professional qualities, experiences and tools to local public administrations to increase the road safety effort in their areas of competence. It is clearly oriented towards the objectives of the road safety policy of the EU to raise the level of road safety, 


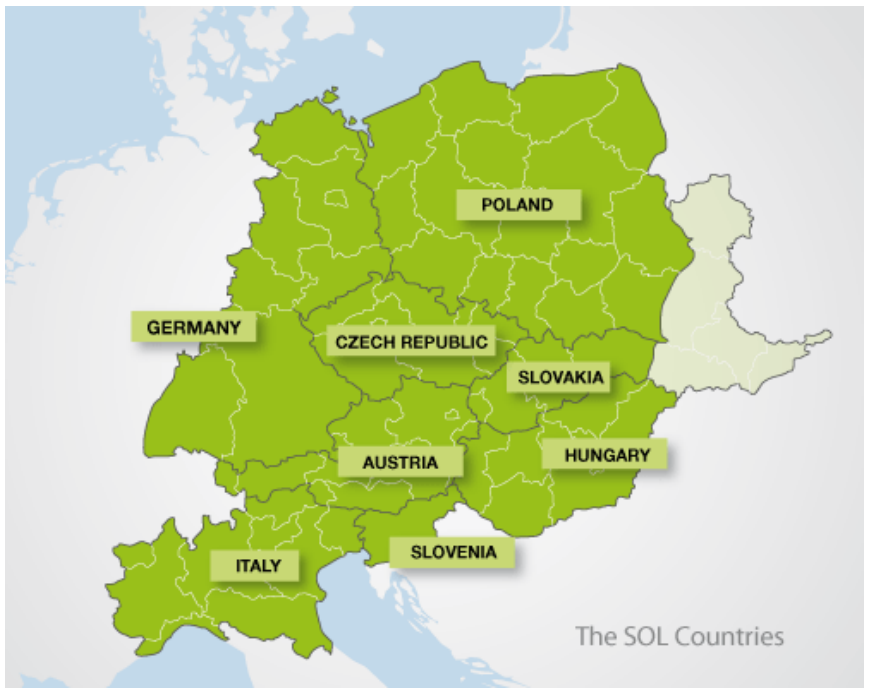

Figure 2: $\quad$ SOL project countires [5].

ensuring safe and clean mobility for citizens everywhere in Europe, and to foster equity among road users through focused efforts to improve the safety of more vulnerable road users. This approach is aimed at reducing the disparities between Member States and providing citizens with a more uniform level of road safety within the EU.

SOL is also linked to global road safety objectives through assisting communities in CEUS to implement the main recommendations of the World Report, including an overall increase of political commitment towards road safety, developing activities based on evidence rather than ad hoc, developing strategies and action plans, allocating resources to the main road safety risks, implementing projects, monitoring and evaluating impacts. SOL is well timed to make a contribution to the achievement of the goals of the Decade of Action for Road Safety 2011-2020.

Road safety and sustainable transport are community issues. Forty percent of fatalities in the EU are in built-up areas. More than $30 \%$ of these deaths are pedestrians. Motorized transport also creates pollution, noise and congestion in built-up areas. The threat of road crashes presents a significant public health and economic problem to communities and influences people's travel choices. According to a report by WHO Europe "Preventing road traffic injury: a public health perspective for Europe" (2004) real and perceived safety concerns are an important barrier preventing many people from choosing walking and cycling as means of transport. Communities that manage their transport systems with road safety, environmental and public health objectives in mind are more liveable, attractive and offer their citizens higher living standards. 
Basic objective of the project is enhancing capacities of local and regional stakeholders to prevent road accidents in Central Europe. Its main goal is jointly develop a strategy of road safety that will support the Central European regions in catching up with highest EU standards in road safety.

SOL is linked to global work - it seeks to assist communities in implementing the main recommendations of the World report on road crash injury prevention (World Bank), including an overall increase of political commitment towards road safety, developing activities based on evidence rather than "ad hoc", developing strategies and action plans, allocating resources to the main road safety risks, implementing projects, monitoring and evaluating impacts.

The SOL Work Programme is designed to generate a continuous cooperation among different levels of administration on one hand, and different local entities from different countries on the other, to build up a network made of vertical and horizontal connections.

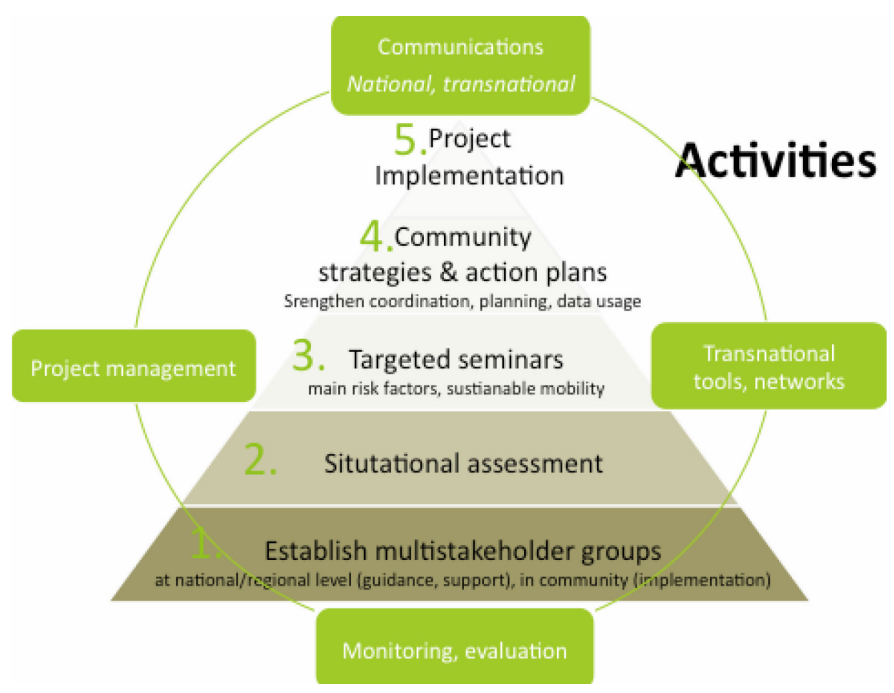

Figure 3: $\quad$ Pyramid model of the SOL project activities [5].

Firstly, a top-down input was applied, as the experts teams reached the local communities and recognized the most active ones in order to supply them with the necessary professional skills and tools to get the awareness of the focal issues concerning their own community. Secondly, the local communities, once endowed with the above described skills and tools, were fostered to get started a stable connection with the upper level in order to communicate the main discovered needs (also thanks to the skills built in the top-down stage) and get an active role in building an action plan and a consequent pilot action, with a bottom-up input.

On the other side, local communities and the technical project teams are networking from a horizontal point of view with local communities from different countries, implementing a real translational cooperation in the field of 
road safety, sharing data and successful practices in order to reduce the number of fatalities on the roads.

\section{Role of road safety management structures}

As was mentioned above one of the main objectives of SOL project was to strengthen road safety management capacity in the region of Central Europe. Currently road safety management structures differ greatly between the countries. In some of them road safety management and coordination structures that involve multiple stakeholders at all levels of government are well developed. In other countries, coordination structures exist at the national level, but not at the community level. In some, structures exist at all levels of government, but they are not operational or their work is not effective enough.

SOL aims to add value to existing structures, where they exist, and to create a mechanism for coordinating a multi-stakeholder road safety intervention where there is a need and no such structure is in place. The main motivation is to ensure the smooth implementation of the SOL project in the country and there may be additional longer-term benefits as well.

As part of the SOL project, two types of multi-stakeholder partnerships were explored in each SOL country - the national advisory group and SOL community partnership.

Basic step for building the national advisory group and SOL community partnership was undertaking a stakeholder assessment.

The first function of the assessment was identifying the main political figures to be involved in SOL national/regional and community partnership in relation to mobilize additional financial support and community backing, as well as those with the relevant technical expertise.

The second important function was examining the remit of all the stakeholders and understanding the relationships between them.

Key objectives of this analysis were:

- Identify key stakeholders, define their characteristics and examine how they will be affected by SOL (e.g. their specific interests, likely expectations in terms of benefits, changes and outcomes);

- Assess their potential influence on the development, and implementation of SOL;

- Understand the relationship between stakeholders and possible conflicts of interest that may arise;

- Assess the capacity of different stakeholders to participate and the likelihood of their contributing to the process;

- Decide how the stakeholders should be involved in the process to ensure the best possible quality and viability of the programme, in particular the nature of their participation (e.g. advisers, consultants or collaborating partners), the form of their participation (e.g. member of working group, advisor or sponsor) and the mode of their participation (e.g. individual participant or representative of a group). 


\section{Road safety situational assessment of Zilina region}

Zilina region which is located in the northwest of Slovakia crosses several significant roads. These roads allow a connection of states: Hungary, Austria, Poland and Czech Republic. Especially roads - E50, E75, E78, and E442 are the most loaded roads in Slovakia - according to the nationwide traffic census on the road network of the Slovak Republic which was realized in 2010. High values of traffic intensity also impact on the value of traffic accidents in the region. The negative trend of accident rate in the Zilina region is the main reason for participation in the project SOL whose implementation should contribute to solving its problems in the area of road safety.

The objective of the SOL community situational assessment was to compile and present the data needed to assess and the road safety situation in Zilina region, including road crash and injury data, institutional capacity, public opinion and knowledge survey, stakeholder map and main conclusions from the analysis.

Table 2: $\quad$ Parts of road safety assessment.

\begin{tabular}{|l|l|}
\hline \multicolumn{1}{|c|}{ Category } & \multicolumn{1}{c|}{ Purpose of the assessment } \\
\hline $\begin{array}{l}\text { Road safety } \\
\text { assessment }\end{array}$ & $\begin{array}{l}\text { To strengthen understanding of the road crash and road crash } \\
\text { injury situation in specific geographical area of the pilot } \\
\text { community. The information is vital for road safety } \\
\text { management and advocacy purposes. }\end{array}$ \\
\hline $\begin{array}{l}\text { Institutional } \\
\text { capacity } \\
\text { assessment }\end{array}$ & $\begin{array}{l}\text { To understand institutional strengths/gaps for delivering and } \\
\text { managing a systems approach to road safety including multi- } \\
\text { stakeholder interventions and for encouraging safe and } \\
\text { sustainable mobility. } \\
\text { To understand training needs of road safety professionals } \\
\text { and community road safety stakeholders }\end{array}$ \\
\hline $\begin{array}{l}\text { Public } \\
\text { opinion } \\
\text { survey }\end{array}$ & $\begin{array}{l}\text { To understand public knowledge, opinion about road safety, } \\
\text { and to understand travel preferences. The road safety plan } \\
\text { must be acceptable to the local population. The results will } \\
\text { help in preparation of the road safety plan reflecting on } \\
\text { expectations of the local population. }\end{array}$ \\
\hline $\begin{array}{l}\text { Stakeholder } \\
\text { map }\end{array}$ & $\begin{array}{l}\text { To identify stakeholders in the community who can } \\
\text { participate in the SOL community teams } \\
\text { contribute to delivery of the SOL and community }\end{array}$ \\
\hline
\end{tabular}

The assessment led to identification of priority issues for action and served as a baseline for monitoring and evaluation of the impact of the SOL project and its interventions in the communities. Its categories are described in Table 2.

The assessment led to identification of priority issues for action and served as a baseline for monitoring and evaluation of the impact of the SOL project and its interventions. 
The complex problem solving of road safety requires a lot of input data and detailed information which are necessary prerequisites for obtaining a common approach of all the interested organizations and representatives from different disciplines of the national economy. Therefore, an emphasis is given on the identification and analysis of the entities involved in the topics related to road safety.

During the analysis were identified goals of respective subjects, their responsibilities (resulting from actual Slovakian National Road Safety Plan for the period 2011-2020.) as well as evaluated their interests, influence and impact in relation to road safety.

By analysis and evaluation of actual situation road safety in Zilina region was found out that the most numerous representations have organizations from transport area at the situational assessment map. The trade-union composition of these entities should enable a complex problem solving of road safety. However, it will be important to determine the system of management and financing, as well as the management entity, control subject, the mutual cross-links and the scope of competence, which should ensure the effective functioning of the system. The range of competitions should be divided between police, stations and services responsible for technical control of vehicles, local and regional authorities, education sector, medias, medical organizations, road administrations, insurance companies, producers and car importers, transport organizations, driving schools, motoring associations, and research and development organizations.

Creation of this management and funding model will not be easy because this model has not been established neither in the territory of Zilina region nor in Slovakia so far. However, it belongs among the priority tasks of the National Plan to increase the Road Safety for the period 2011 to 2020.

\section{Conclusions}

Global, European and regional best examples show that road crash and road trauma prevention can be sustainable. Many countries show similar weaknesses in dealing with road safety issues on the political and technical levels. Political commitment, professional capacity and institutional structures are not robust enough to stem the growing number of deaths and injuries from road crashes. Therefore a transnational working approach is favoured in order to facilitate mutual learning processes that envisage a higher level of professionalism in dealing with this issue.

The SOL project is timely since growing awareness of the human and economic cost of the rising toll of death and injury on the world's roads has led to road safety rising up the political agenda internationally. Experience in countries that have achieved substantial improvements in road safety despite continuing traffic growth has shown that a key requirement is for road safety to be recognized as a top priority at the highest political level. Death and injury on a nation's roads must be seen as unacceptable causing huge human costs as well as economic losses. Improved road safety makes a major contribution to the 
quality of life in a country, particularly for children and young people who are so often the casualties. The SOL project is underpinned by the knowledge that the seemingly inexorable trend that increased motorization results in more casualties has been arrested and reversed in many developed countries, and solutions to the road safety problem are available and well known. With a concerted effort in all countries lives can be saved.

\section{References}

[1] Wegman, F., Siem, O., Benchmarking road safety performances of countries, Safety Science 48, 2010

[2] Mikusova, M., Value of networking in transport policy related to the road safety, Modern transport telematics, Jerzy Mikulski (Ed.) $11^{\text {th }}$ International Conference on Transport Systems Telematics, TST 2011, KatowiceUstron, Poland, October 2011, Selected Papers, Germany: SpringerVerlag, pp. 70-77, 2011

[3] Towards Zero - Ambitious Road Safety Targets and the Safe System Approach. Transport research Centre, OECD/ITF, Paris, 2008.

[4] World report on road traffic injury prevention. World Health Organization, Geneva, 2004

[5] SOL, www.sol-project.eu

[6] International Transport Forum, www.internationaltransportforum.org

[7] European Transport Safety Council, www.etsc.eu

[8] Make Roads Safe - The Campaign for Global Road Safety, www.makeroadssafe.org

[9] TISPOL, www.tispol.org

[10] A Challenging Start towards the EU 2020 Road Safety Target - 6th Road safety PIN report, http://www.etsc.eu/documents/PIN_Report_6_web.pdf

[11] Global Status Report on Road Safety 2013 (WHO), http://www.who.int /roadsafety/decade_of_action/en/ 